\title{
Frequency of Red Blood Cells Alloimmunization in Thalassemia Patients at King Abdulaziz University Hospital in Jeddah, Saudi Arabia
}

\author{
Salwa A. Al Najjar ${ }^{1}$, mPHIL, PhD, Taher M. Tayeb², MBBS, Abdulrahman S. Alboog ${ }^{3}$, \\ MBBS, Tarek M. Elgemmezi ${ }^{4}$, MS, MoPH, and Salwa I. Hindawi ${ }^{1,4}$, MRCPath, FRCPath \\ 'Department of Hematology, Faculty of Medicine, King Abdulaziz University, Jeddah Saudi Arabia \\ ${ }^{2}$ Department of Medicine, George Washington University, Washington, DC, U.S.A. \\ ${ }^{3}$ Department of Anesthesia, Faculty of Medicine, University of Jeddah, Jeddah, Saudi Arabia \\ ${ }^{4}$ Blood Transfusion Services, King Abdulaziz University, Jeddah, Saudi Arabia
}

\section{Correspondence}

Dr. Salwa A. Al Najjar

Department of Hematology

Faculty of Medicine, King Abdulaziz University

P.O. Box 80215, Jeddah 21589

Saudi Arabia

e-M: salwa03@yahoo.com

Submission: 14 Oct. 2019

Accepted: 09 Dec. 2019

\section{Citation}

Al Najjar SA, Tayeb TM, Alboog AS, Elgemmezi TM, Hindawi SI. Frequency of red blood cells alloimmunization in thalassemia patients at King Abdulaziz University Hospital in Jeddah, Saudi Arabia. JKAU Med Sci 2019; 26 (2): 1-8. DOI: 10.4197/Med.26-2.1

Copyright: (T) The Author(s), YEAR. Publisher. The Journal of King Abdualziz University - Medical Sciences is an Official Publication of "King Abdulaziz University". It is an open-access article distributed under the terms of the Creative Commons Attribution Non-Commercial License, which permit unrestricted non-commercial use, distribution, and reproduction in any medium, provided the original work is properly cited.

\begin{abstract}
The aim of the study is to assess the alloimmunization rate to red blood cell in thalassemia patients at King Abdulaziz University Hospital. Thalassemia is the most common genetic disorder worldwide that represents a major public health problem and requires long life blood transfusion to the patients as the main treatment. Alloimmunization to the transfused red blood cell can cause hemolytic transfusion reactions and significantly complicate transfusion therapy. Screening and identification of alloantibodies and transfusion of extended phenotyped blood can minimize these risks. A retrospective study was conducted on 134 thalassemia patients at King Abdulaziz University Hospital in Jeddah. Patients'samples were subjected to red cell typing, antibody screening and identification of red blood cell antibodies. Alloimmunization in thalassemia patients was $20.15 \%$; antibodies were mainly to the Rh and Kell blood group systems, the highest rate was for anti-E (32.4\%) followed by anti-K (21.6\%). Alloimmunization rate was the highest in the age group from > $10-20$ years (40.7\%). Red cell alloimmunization is a frequent event among thalassemia patient. A national protocol for screening and identifying of the red cell alloantibodies and transfusion of phenotype blood is required for proper management of these patients.
\end{abstract}

\section{Keywords}

Transfusion; Thalassemia; Alloimmunization; Phenotyping 


\section{Introduction}

$T$ he thalassemia major is the most common inherited hemoglobin disorder that results from diminished production of beta globin chains, resulting in increase of alpha globin chains. Beta ( $\beta$ ) thalassemia is characterized by ineffective erythropoiesis and eventually shortened red blood cells (RBCs) life span ${ }^{[1]}$.

Beta ( $\beta$ ) thalassemia major is commonly discovered within the first year of life in the majority of the patients. The disorder is mainly concentrated across the Middle East, India and Southeast Asia, with over 250 million carriers worldwide ${ }^{[2]}$. The disease is treated by lifelong regular blood transfusions (every 2-3 weeks) to increase patients' hemoglobin level ${ }^{[3]}$. Although these transfusions were proven to be successful measures for the survival and development of thalassemia patients, it was also associated with the risk of alloimmunization ${ }^{[4,5]}$, a status where the recipient develops alloantibodies against the transfused RBCs and becomes at risk of developing catastrophic hemolytic reactions ${ }^{[6-8]}$ This presents a serious challenge for the pretransfusion testing procedures and the overall safety of transfusions ${ }^{[6]}$ and has mobilized many researchers to estimate the prevalence of alloimmunization in endangered thalassemia patients. The reported rates of alloimmunization ranged between $4 \%$ to $50 \%{ }^{[3,9-11]}$. These variations are attributed to several elements thought to be responsible for the rate of alloimmunization, including the ethnic variations for the RBC antigens among blood donor and the recipients and the response of the immune system of the patient and the immune-modulatory effects of the allogenic transfusions on the recipient's immune status $^{[5]}$.

Exploring the responsible factors for alloimmunization can aid in determining a suitable approach to minimize alloimmunization frequency.

This paper aimed to determine the rate of RBC alloimmunization in an ethnically diverse population of thalassemia patients attending a tertiary care hospital in Saudi Arabia, to detect the prevalence of RBCs typing and to identify the specificities of alloantibodies among the patients. This is done to ensure that appropriate action is taken to reduce alloimmunization and minimize the risk of hemolytic transfusion adverse events in thalassemia patients.

\section{Materials and Methods}

A retrospectivestudy was conducted on 134thalassemia patients at King Abdulaziz University Hospital (KAUH), from the year 2014 to 2017 that included diagnosed patients with thalassemia major, followed at $\mathrm{KAUH}$ hematology outpatient clinics, irrespective of their age or gender. Data of the patients was collected according to the ethical approval at KAUH; which was obtained from KAUH Ethical and Technical Committee (No. 131613). All patients provided written informed consent and were assured about the confidentiality of their personal information. A data extraction sheet was designed to collect patients' information from their medical records including demographics: age, gender and nationality; hematological profile: such as their blood group, transfusion history, history of splenectomy; and lastly data on antibody formation including the rate of alloimmunization against the different blood group antigens. Patients were classified into: Males and females, Saudi and non-Saudi and into five age groups; from 0 to 10 years, from $>10$ to 20 years, from $>20$ to 30 years, from $>30$ to 40 years and $>40$ years old.

Patients planned for transfusion were targeted and then were tested for alloimmunization according to the protocols followed by KAUH. Ethylenediaminetetraacetic acid (EDTA) blood samples ( $3 \mathrm{ml}$ each) were drawn from the patients prior to transfusion, and RBCs were serologically phenotyped before transfusion. After that, the separated plasma of the patients was subjected to screening for the presence of RBCs alloantibodies with polyspecific antihuman globulin. Gel Column Agglutination Technology at $37^{\circ} \mathrm{C}$ was used for detection of antibodies. Alloantibody screening was performed using three red cells' screening panels (automated Ortho machine); positive screening samples were tested manually to identify the specificity of antibodies; to be against Rh system, Kell, Duffy, Kidd, Lewis, MNSs, P1 or others ${ }^{[14]}$. Antibody identification was performed using commercial 11 red cells' panels (Bio-Rad Laboratories, Inc., Hercules, CA USA).

Screening and identification panels of red cells were the commercially available $\mathrm{O}$ cells that were fulfilling the international specification for proper detection of antibodies ${ }^{[14]}$. 


\section{Transfusion Protocol}

All patients were transfused at KAUH according to local transfusion policy. patients were transfused with $A B O / R h D$ compatible blood after cross matching. Phenotypically matched units were issued whenever known. In case a patient was detected to have alloantibodies; antigen negative units that were compatible on full serologic cross match were issued ${ }^{[14]}$.

\section{Statistical Analysis:}

The IBM Statistical Package for Social Sciences (SPSS) was used for Windows, Version 20. (IBM Corp., Armonk, NY USA). Data were described in counts and frequencies, while continuous data were presented in means and standard deviations. Comparative analysis was performed between alloimmunized and non alloimmunized patients, and across all measured parameters. Chi-squared test and Fisher's exact test have been used to test the difference between groups. A P-value ( $\geq 0.05$ ) was significant.

\section{Results}

The alloimmunization rate among 134 patients was 20.15\% (27 cases). Males represent 72 (53.7\%) cases and females represent 62 (46.3\%) cases; 13 male patients were alloimmunized representing $48.1 \%$ of the alloimmunized patients, while 14 female patients were alloimmunized representing $51.9 \%$ of the alloimmunized patients (Table 1, P-value was 0.514).

The Saudi thalassemia patients were 35 (26.1\%) cases while the non-Saudi were 99 (73.9\%) cases. Four cases of the Saudi patients were alloimmunized representing $14.8 \%$ of the alloimmunized patients, while 23 cases of the non-Saudi patients were alloimmunized representing $85.2 \%$ of the alloimmunized patients (Table 2, P-value was 0.134).

According to the age groups; patients from 0 to 10 years were $5(3.7 \%)$ cases, from $>10$ to 20 years were $48(35.8 \%)$ cases, from $>20$ to 30 years were $48(35.8 \%)$ cases, from > 30 to 40 years were $29(21.7 \%)$ cases and $>40$ years old were 4 (3\%) cases. The alloimmunization

Table 1. The rate of alloimmunization according to the gender of the patients

\begin{tabular}{|l|c|c|}
\hline \multicolumn{1}{|c|}{ Gender } & Number (\%) & Alloimmunized \\
\hline Male & $72(53.7 \%)$ & $13(48.1 \%)$ \\
\hline Female & $62(46.3 \%)$ & $14(51.9 \%)$ \\
\hline Total & 134 & 27 \\
\hline
\end{tabular}

Table 2. The rate of alloimmunization according to the nationality of patients

\begin{tabular}{|l|c|c|}
\hline \multicolumn{1}{|c|}{ Nationality } & Number (\%) & Alloimmunized \\
\hline Saudi & $35(26.1 \%)$ & $4(14.8 \%)$ \\
\hline Non-Saudi & $99(73.9 \%)$ & $23(85.2 \%)$ \\
\hline \multicolumn{1}{|c|}{ Total } & 134 & 27 \\
\hline \multicolumn{2}{|r|}{} \\
\hline
\end{tabular}

Table 3. The rate of alloimmunization according to the age groups of the patients

\begin{tabular}{|c|r|c|}
\hline Age Group & Number (\%) & Alloimmunized \\
\hline $0-10$ & $5(3.7 \%)$ & $1(3.7 \%)$ \\
\hline$>10-20$ & $48(35.8 \%)$ & $11(40.7 \%)$ \\
\hline$>20-30$ & $48(35.8 \%)$ & $8(29.7 \%)$ \\
\hline$>30-40$ & $29(21.7 \%)$ & $7(25.9 \%)$ \\
\hline$>40$ & $4(3.0 \%)$ & 0 \\
\hline $0-10$ & $5(3.7 \%)$ & $1(3.7 \%)$ \\
\hline
\end{tabular}

in the patients of the age group 0 to 10 years was 1 case representing 3.7\% of the alloimmunized patients, 11 cases in the age group $>10$ to 20 years representing $40.7 \%$ of the alloimmunized patients, 8 cases in the age group $>20$ to 30 years representing $29.7 \%$ of the alloimmunized patients, 7 cases in the age group $>30$ to 40 years representing $25.9 \%$ of the alloimmunized patients and there were no alloimmunized patients above 40 years old (Table 3, P-value was 0.610).

The $A B O / D$ blood grouping frequencies among patients were: O-positive: 55 (41\%) cases, A-positive: $42(31.3 \%)$ cases, B-positive: 24 (17.9\%) cases, ABpositive: 5 (3.7\%) cases, O-negative: $6(4.5 \%)$ cases and A-negative: 2 (1.5\%) cases. Eleven cases of blood group O-positive were alloimmunized which represent $40.7 \%$ of the alloimmunized patients, 10 cases of blood group A-positive were alloimmunized which represent 37\% of the alloimmunized patients, 4 cases of blood group B-positive were alloimmunized which represent 14.8\% of the alloimmunized patients, 1 case of blood group AB-positive was alloimmunized which represent 3.7\% of the alloimmunized patients and 1 case of blood group A-negative was alloimmunized which represent $3.7 \%$ of the alloimmunized patients. Blood group $\mathrm{O}$ was the most common followed by group A. (P-value was 0.225).

The prevalence of alloantibodies found in these patients was 37 antibodies; which have a rate of anti-E: $12(32.4 \%)$, anti-K: 8 (21.6\%), anti-C: 7 (18.9\%), anti-c: 2 (5.4\%), anti-Fya: 2 (5.4\%); moreover anti-e, anti-D, antiFyb, anti-Jka , anti-Jkb and anti-Lua were found one time (2.7\%); (Fig. 1). 


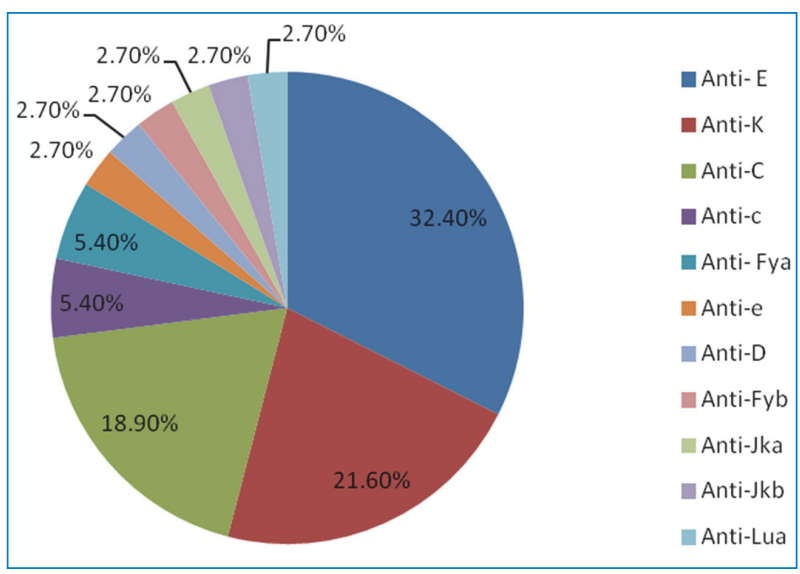

Figure 1. The prevalence of red blood cells alloantibodies.

\section{Discussion}

Frequent blood transfusion is the main treatment for thalassemia patients, in order to minimize the complications of severe anemia. The beneficial effects of transfusions over the long term must be weighed against the risks of hemosiderosis, viral infections and alloimmunization against RBCs.

This paper reported an alloimmunization prevalence of $27 / 134$ (20.15\%) in the thalassemia patients, belonging mainly to the Rh and Kell systems. The frequency of alloimmunization depends on the heterogeneity of the donor-recipient population and the RBC administration matching process. Numerous studies have reported a wide frequency range of alloimmunization in thalassemia patients: $30 \%$ (57/190) in Kuwait, 4.97\% (8/161) in India, 5\% (72/1435) in Italy, $26.25 \%(84 / 320)$ in Egypt, 22.06\% (16/68) in Saudi Arabia and 3.7\% (44/1200) in Greece $e^{[10-13,15-21]}$.

In this study, the most common antibody implicated was Anti-E followed by Anti-K and Anti-C. The highest rate of alloimmunization was in the age group > $10-20$ years that represents $40.7 \%$ of the alloimmunized patients.

The rate of alloimmunization in the thalassemia patients was shown to be high in this study (20.15\%), as most of those patient were referred to this hospital after they had already developed alloantibodies; they were receiving frequent transfusions of non-phenotypically matched blood units in other centers that do not follow local or international guidelines regarding the management of chronically multi-transfused patients, as there is no clear national protocol for this. Those patients who developed antibodies are now receiving phenotyped blood in this hospital to prevent hemolytic transfusion reactions.

Gaining knowledge of the frequency of RBC antigen phenotypes in this population will allow establishment of a comprehensive donor and patient blood database that can be used to match those patients with phenotypically similar donors, to minimize the risks of alloimmunization in thalassemia patients.

Molecular bases of almost all the major blood group antigens has been determined enabling development of DNA-based methods for determining blood group genotype. DNA-based blood group typing provides a valuable adjunct to traditional methods of pretransfusion testing especially for recently transfused thalassemia patients for whom phenotyping of RBCs is difficult or irrelevant.

Alternative treatment options to blood transfusion for thalassemia patients may also be considered, such as stem cell transplantation.

Other promising therapeutic strategies for thalassemia patients have recently been developed, which includegenetic and pharmacological approaches to ameliorating ineffective erythropoiesis ${ }^{[22]}$.

\section{Conclusion}

Alloimmunization to red cell antigens is a frequent complicationamong thalassemia patients in developing countries. Rh and Kell blood group antibodies are most commonly expressed with other RBC antibodies also clinically implicated from this report.

This study re-emphasizes the need for typing RBCs antigens for thalassemia patients prior to first transfusion and finding the most suitable blood, especially for Rh and K antigens. Proper documentation of the results and investigations done for thalassemia patients is essential for systemic follow up and treatment that would ultimately lead to safe blood transfusion and better quality of life.

\section{Recommendations}

- A national protocol for screening and identifying of the red cell alloantibodies is required for all thalassemia patients 
Frequency of Red Blood Cells Alloimmunization in Thalassemia Patients at King Abdulaziz University Hospital in Jeddah, KSA SA. Al Najjar et al.

- Extended phenotyped matched PRBC transfusions should be implemented in all hospitals as a feasible method to minimize the risk of alloimmunization.

\section{Conflict of Interest}

The authors have no conflict of interest.

\section{Disclosure}

The authors did not receive any type of commercial support either in forms of compensation or financial for this study. The authors have no financial interest in any of the products or devices, or drugs mentioned in this article.

\section{Ethical Approval}

The study design was reviewed and approved by the Unit of Biomedical Ethics Research Committee at King Abdulaziz University.

\section{Acknowledgement}

The authors thank all the contributing staff in the blood transfusion services and hematology department at KAUH.

\section{References}

[1] Srinoun K, Svasti S, Chumworathayee W, Vadolas J, Vattanaviboon P, Fucharoen S, Winichagoon P. Imbalanced globin chain synthesis determines erythroid cell pathology in thalassemic mice. Haematologica 2009; 94(9): 12111219.

[2] De Sanctis V, Kattamis C, Canatan D, Soliman AT, Elsedfy H, Karimi M, Daar S, WaliY, Yassin M, Soliman N, Sobti P, Al Jaouni S, El Kholy M, Fiscina B, Angastiniotis M. $\beta$-thalassemia distribution in the old world: an ancient disease seen from a historical standpoint. Mediterr J Hematol Infect Dis 2017; 9(1): e2017018.

[3] Wang LY, Liang DC, Liu HC, Chang FC, Wang CL, Chan YS, Lin M. Alloimmunization among patients with transfusion dependent thalassemia in Taiwan. Transfus Med 2006; 16(3): 200-203.

[4] Galanello R, Origa R. Beta-thalassemia. Orphanet J Rare Dis 2010; 5: 11.

[5] Dhawan HK, Kumawat V, Marwaha N, Sharma RR, Sachdev S, Bansal D, Marwaha RK, Arora S. Alloimmunization and autoimmunization in transfusion dependent thalassemia major patients: Study on 319 patients. Asian J Transfus Sci 2014; 8(2): 84-88.
[6] Chou ST, Liem RI, Thompson AA. Challenges of alloimmunization in patients with haemoglobinopathies. Br J Haematol 2012; 159(4): 394-404.

[7] Pandey H, Das SS, Chaudhary R. Red cell alloimmunization in transfused patients: A silent epidemic revisited. Asian J Transfus Sci 2014; 8(2): 75-77.

[8] Kruatrachue M, Sirisinha S, Pacharee P, Chandarayingyong D, Wasi P. An association between thalassaemia and autoimmune haemolytic anaemia (AlHA). Scand J Haematol 1980; 25(3): 259-263.

[9] Sirchia G, Zanella A, Parravicini A, Morelati F, Rebulla P, Masera G. Red cell alloantibodies in thalassemia major. Results of an Italian cooperative study. Transfusion 1985; 25(2): 110-112.

[10] Singer ST, Wu V, Mignacca R, Kuypers FA, Morel P, Vichinsky EP. Alloimmunization and erythrocyte autoimmunization in transfusion-dependent thalassemia patients of predominantly Asian descent. Blood 2000; 96(10): 33693373.

[11] Pahuja S, Pujani M, Gupta SK, Chandra J, Jain M. Alloimmunization and red cell autoimmunization in multitransfused thalassemics of Indian origin. Hematology 2010; 15(3): 174-177.

[12] el-Danasoury AS, Eissa DG, Abdo RM, Elalfy MS. Red blood cell alloimmunization in transfusion dependent Egyptian patients with thalassemia in a limited donor exposure program. Transfusion 2012; 52(1): 43-47.

[13] Ameen R, Al-Shemmari S, Al-Humood S, Chowdhury Rl, Al-Eyaadi O, Al-Bashir A. RBC alloimmunization and autoimmunization among transfusion-dependent Arab thalassemia patients. Transfusion 2003; 43(11): 1604-1610.

[14] Poole J, Daniels G. Blood group antibodies and their significance in transfusion medicine. Transfus Med Rev 2007; 21(1): 58-71

[15] Gader AG, Al Ghumlas AK, Al-Momen AK. Transfusion medicine in a developing country - alloantibodies to red blood cells in multi-transfused patients in Saudi Arabia. Transfus Apher Sci 2008; 39(3): 199-204.

[16] Keramati MR, Shakibaei H, Kheiyyami MI, Ayatollahi H, Badiei Z, Samavati M, Sadeghian MH. Blood group antigens frequencies in the northeast of Iran. Transfus Apher Sci 2011; 45(2): 133-136.

[17] Thakral B, Saluja K, Sharma RR, Marwaha N. Phenotype frequencies of blood group systems (Rh, Kell, Kidd, Duffy, MNS, P, Lewis, and Lutheran) in North Indian blood donors. Transfus Apher Sci 2010; 43(1): 17-22.

[18] Bilwani F, Kakepoto GN, Adil SN, Usman M, Hassan F, Khurshid M. Frequency of irregular red cell alloantibodies in patients with thalassemia major: a bicenter study. J Pak Med Assoc 2005; 55(12): 563-565.

[19] Alboog AS, Tayeb TM, Alsager MO, AINajjar SA, Damanhouri GA, Jarullah JS, Hindawi SI. Red blood cell alloimmunization in sickle cell disease patients in Jeddah, Saudi Arabia: a pilot study. J KAU Med Sci 2015; 22(3): 17-22. 
[20] Ghasemi A, Abbasian S, Ghaffari K, Salmanpour Z. Prevalence of alloantibodies and autoantibodies in transfusion dependent thalassemia patients. IJBC 2016; 8(3): 80-85.

[21] Shah S, Shah M, Gajjar M, Bhatnagar N, Soni S, Shah M. Frequency of alloantibody in multiple-transfused thalassemia major patients and factors influencing on alloimmunization: Alloimmunization in thalassemia patient. Nat J Integr Res Med 2016; 7(1): 40-46.

[22] Cappellini MD, Porter JB, Viprakasit V, Taher AT. A paradigm shift on beta-thalassemia treatment: how will we manage this old disease with new therapies? Blood Rev 2018; 32(4): 300-311. 


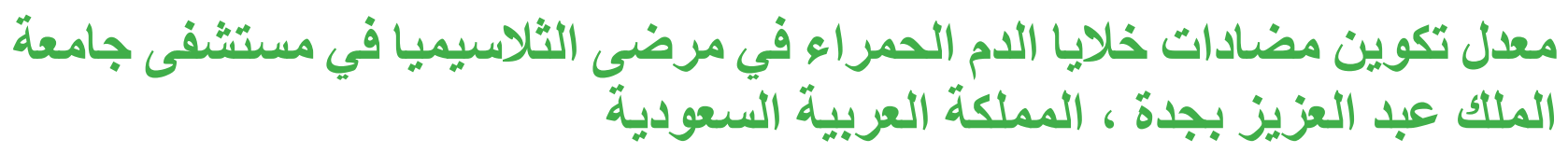

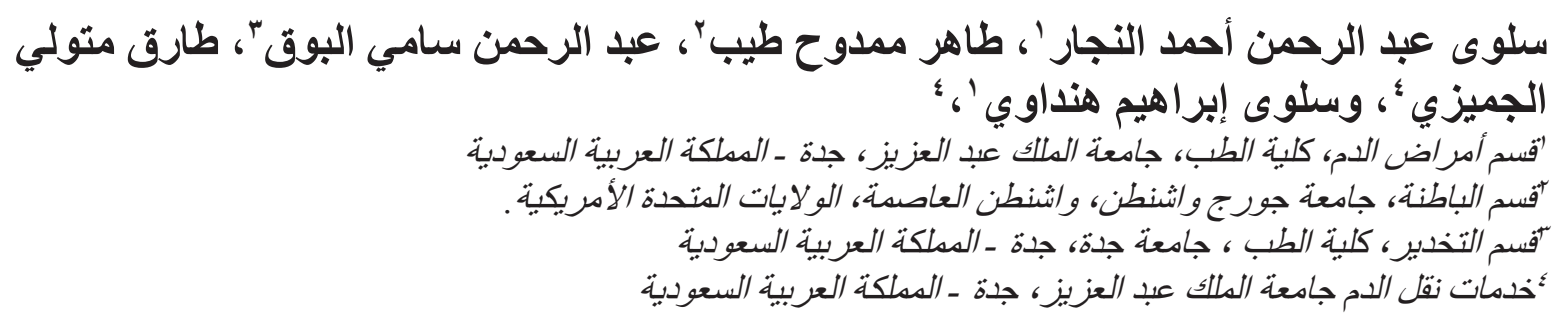

المستخلص. بهدف در اسة معدل تكوين مضادات كريات الدم الحمر لمرضي الثنلاسيميا بمستشفي جامعة الملك عبد العزيز الذين يتم نقل الدم لهم بشكل منتظم.

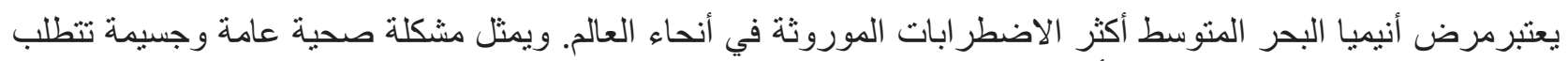

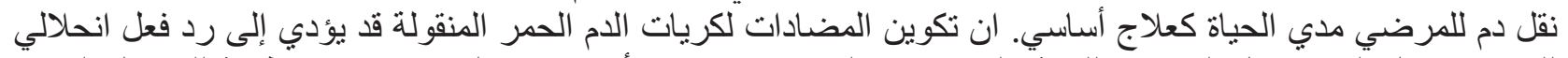

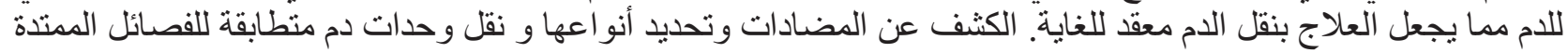
للمريض يقلل من تللك المخاطر.

تم إجر اء در اسة مرجعية لعدد ع ا أمريض ثلاسيميا بمستشفي جامعة الملك عبد العزيز بجدة، تم من خلالها فحص فصائل

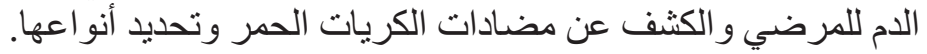

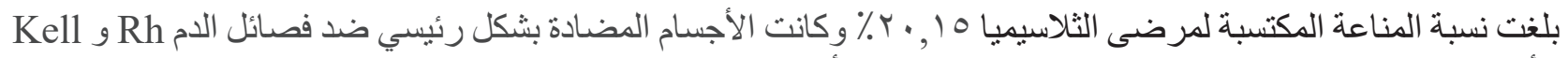

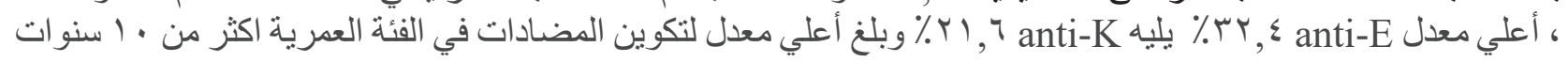

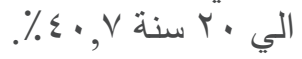

ان تكوين مضادات لفصائل كريات الدم الحمر يعد أمر ا واردا بشكل كبير في مرضي الثثلاسيميا. مما يتطلب وجود دود بروتوكول وطني لفحص وتحديد الأجسام المضادة لخلايا الام الحمر و نقل وحدات دم منطابقة للفصائل الممتدة للمرضي لادئل الدارة سليمة لهؤلاء المرضي. 
